

\title{
Restoran Deneyiminden Memnuniyet Potansiyelinin Belirlenmesinde "Gülez Yöntemi" nin Kullanılmasına Yönelik Bir Model Önerisi
}

Arş. Gör. Dr. Sami Sonat ÖZDEMIR, Balıkesir Üniversitesi, Turizm Fakültesi, Balıkesir, e-posta: ssonatozdemir@balikesir.edu.tr

ORCID: https://orcid.org/0000-0003-4796-6083

$\ddot{O} z$

$\mathrm{Bu}$ çalışma, restoranların tüketiciyi memnun etme potansiyelini somut olarak ortaya koyacak bir yöntem geliştirilmesini amaçlamaktadır. Bu doğrultuda öncelikle restoran deneyiminden memnuniyeti etkileyen faktörler, ilgili literatür yardımıyla ortaya koyulmaya çalışılmıştır. Gerçekleştirilen literatür taramasında, tüketicilerin restoran deneyiminden memnuniyetlerini belirleyen faktörlerin, yiyecek ile ilgili faktörler, hizmet ile ilgili faktörler, atmosfer ile ilgili faktörler ve kolaylık başlığı altında yer alabilecek diğer faktörler olmak üzere gruplandırıldığı görülmüş̧tür. Söz konusu faktörlere dahil olan çeşitli özellikler, literatürde yer alan konu ile ilgili çalışmalarda ele alınma sıklığına bağlı olarak sıralanmıştır. İlk olarak Gülez (1990) tarafından orman içi rekreasyon potansiyelinin belirlenmesine ilişkin oluşturulan modelin, söz konusu faktörlere yönelik memnuniyet düzeylerinin belirlenebilmesi amaciyla uyarlanmasıyla, bir restoranın tüketicileri memnun etme potansiyelini belirlemek için kullanılabilecek bir yöntem ortaya koyulması hedeflenmiştir. Böylece, tüketicilerin restoranların yaşattığı deneyimden memnuniyetleri analiz edilerek, sözü geçen restoranların tüketici memnuniyeti yaratma potansiyeli başlığı altında somut bir değer elde edilmesi sağlanabilecektir. Çalışmadan elde edilen bulgular, restoran deneyiminden memnuniyet potansiyelini belirlemek üzere oluşturulan modelde yer alan faktörlerin, ilgili literatürü yansıtma kapasitesine sahip olduğunu göstermekte, ayrıca modelin bu doğrultuda kullanılabilmesi adına sahip olduğu avantaj ve dezavantajlar ortaya koyulmaktadır. Bununla birlikte oluşturulan modelin bir restoranın tüketiciyi memnun etme potansiyeline dair somut verileri ortaya koymaktaki başarısının, modelin gelecek çalışmalarda restoran ziyaretçilerinden elde edilecek verilerin test edilmesiyle, etkin bir şekilde değerlendirilebileceği de ortaya koyulmaktadır.

Anahtar Kelimeler: Restoran Deneyimi, Memnuniyet, Gülez Yöntemi.

Makale Gönderme Tarihi: 01.10.2020

Makale Kabul Tarihi: 05.03.2021

Önerilen Atıf:

Özdemir, S. S. (2021). Restoran Deneyiminden Memnuniyet Potansiyelinin Belirlenmesinde "Gülez Yöntemi" nin Kullanılmasına Yönelik Bir Model Önerisi, Türk Turizm Araştırmaları Dergisi, 5(1): 299-312.

(C) 2021 Türk Turizm Araştırmaları Dergisi. 


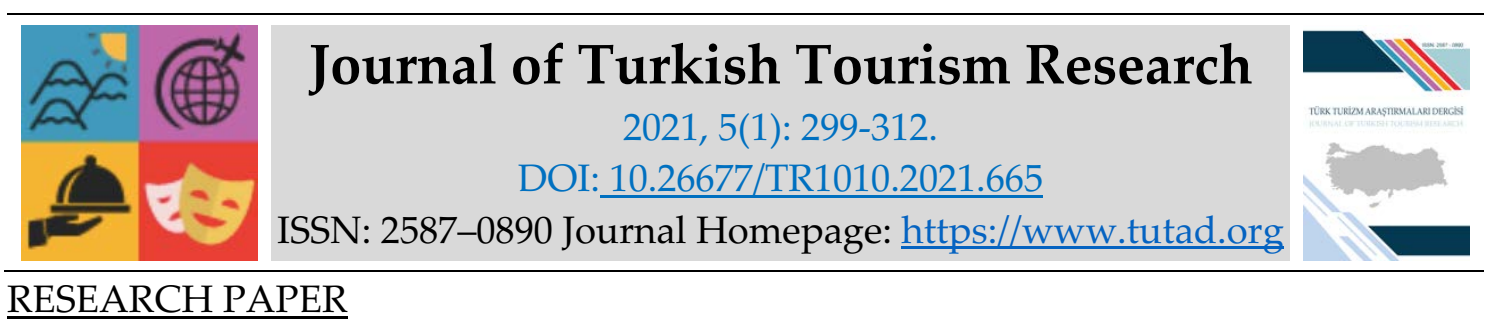

\title{
A Model Proposal for The Use of "Gülez Method" in Determining Satisfaction Potential from Restaurant Experience
}

Dr. Sami Sonat ÖZDEMIR, Balıkesir University, Faculty of Tourism, Balıkesir, e-mail: ssonatozdemir@balikesir.edu.tr

ORCID: https://orcid.org/0000-0003-4796-6083

\begin{abstract}
This study aims to develop a method that will concretely reveal the potential of restaurants to satisfy the consumer. In the literature review, it was seen that the factors determining the satisfaction of consumers with the restaurant experience were grouped as food-related factors, service-related factors, atmosphere-related factors and other factors that could be included under the heading of convenience. Various factors included in the aforementioned titles are listed depending on the frequency of being addressed in studies on the subject in the literature. Firstly, the model created by Gülez (1990) to determine the recreation potential in the forest was adapted to determine the satisfaction levels for these factors. Thus, by analyzing the satisfaction of the consumers from the restaurant experience, it aimed to create a concrete value under the heading of the potential of the restaurants to create consumer satisfaction. Within the scope of the study, it was evaluated that the factors in the model created to determine the potential of satisfaction from the restaurant experience have the capacity to reflect the relevant literature. In addition, the advantages and disadvantages of the model are revealed. In addition, it is also revealed that the success of the model can be evaluated effectively by future studies, testing the data obtained from restaurant visitors.
\end{abstract}

Keywords: Restaurant Experience, Satisfaction, Gülez Method.

Received: 01.10 .2020

Accepted: 05.03.2021

\section{Suggested Citation:}

Özdemir, S. S. (2021). A Model Proposal for The Use of "Gülez Method" in Determining Satisfaction Potential from Restaurant Experience, Journal of Turkish Tourism Research, 5(1): 299312.

(C) 2021 Türk Turizm Araştırmaları Dergisi. 


\section{Gíriş}

Restoran işletmelerinin rekabet edebilirliği operasyonel etkinliğin varlığına, söz konusu etkinliği sağlanması da büyük ölçüde restoran deneyimi yaşayan tüketicilerin memnuniyetlerine bağlıdır (Lee ve Hing, 1995). Restoran deneyiminden memnuniyet düzeyi ise tüketicilerin davranışsal niyetlerini etkilemektedir. Bu durum tüketicilerin restoran deneyiminden memnuniyetlerinin, restoran işletmeleri için önemini ortaya koymaktadır.

Literatürde restoran deneyiminden memnuniyet düzeyinin belirlenebilmesi için gerçekleştirilen çalışmalar, tüketicilerin belirli bir restoranda yaşadıkları deneyimden memnuniyet düzeylerini ortaya koymakta ancak araştırmaya konu olan restoranın tüketicileri memnun etme düzeyine dair somutlaştırılmış bir istatistik sunmamaktadır. Bu çalışma kapsamında, restoranların tüketiciyi memnun etme potansiyelinin somut bir istatistik ile ortaya koyulabilmesi hususundaki eksikliğin ortadan kaldırılabilmesi hedefleri doğrultusunda bir yöntem geliştirilmesi amaçlanmiştır.

Çalışmada ilk olarak, restoran deneyiminden memnuniyeti etkileyen unsurlar ve bu unsurların memnuniyete etkisi literatür taraması yardımıyla belirlenmiştir. Gerçekleştirilen literatür taramasinda restoran deneyiminden memnuniyeti etkileyen unsurlar olarak, yiyecek ile ilgili unsurlar, hizmet ile ilgili unsurlar, atmosfer ile ilgili unsurlar ve özellikle fiyat uygunluğu ve fiziksel olanakları içeren diğer unsurlar ön plana çıkmıştır. Söz konusu literatür taramasıyla, restoran memnuniyeti etkileme kapasitesi en yüksek olan faktörlerin ortaya koyulması amaçlanmıştır. Daha sonra ilgili faktörler Gülez yöntemi temel alınarak geliştirilen modele yerleştirilmiştir.

Gülez yöntemine dayanarak oluşturulan modelde yer alan faktörlere ilişkin puanlamalar yapılırken ilgili faktörlerin puan ağırlıkları literatürde yer alma sıklığına bağlı olarak belirlenmiş, bu sayede restoran deneyiminden müşteri memnuniyetini etkileyen faktörleri büyük bir oranda temsil eden ve restoranların sundukları deneyim ile tüketicileri ne oranda memnun etme potansiyeline sahip olduklarını belirleyen veya bu potansiyelin gelecekte ne şekilde değiştirebileceklerini gösteren bir yöntem ortaya koyulmuştur.

\section{KAVRAMSAL ÇERÇEVE}

\section{Restoran Deneyiminden Memnuniyet Unsurları}

Restoran sektöründe tüketici memnuniyetinin önemi, sıklıkla restoran faaliyetlerinin verimliliği ve rekabet avantajı ile ilişkilendirilmiştir (Almanza vd., 1994; Lee ve Hing, 1995; Oh ve Jeong, 1996; Qu, 1997; Bilgin, 2017; Uslu, 2020). Tüketicilerin restoran deneyiminden memnuniyetlerinin, restoran verimliliğine ve rekabet avantajına etkisine yönelik belirleyici ise, tekrar ziyaret, tavsiye ve şikâyet doğrultusundaki davranışsal niyetlerdir. (Kivela vd., 1999; 2000; Bei ve Chiao, 2001; Xia vd., 2004; Tran, 2020).

Tüketicilerin restoran deneyiminden memnuniyetlerini ve dolayısıyla davranışsal niyetlerini şekillendiren unsurlar ve bu unsurların görece önemi, literatürde yer alan araştırmalar kapsamında ele alınmıştır. Söz konusu çalışmalar içerisinde Reuland vd. (1985), ağırlama hizmetlerinin, ürün, çalışanların tutum ve davranışları ile çevre olmak üzere üç ana unsurun birleşiminden meydana geldiğini ileri sürmüştür. Berry vd., (2002)'nin çalışması da bu görüşü destekler niteliktedir. Bu yaklaşımlar, restoranlar özelinde müşteri memnuniyeti yaratma kapasitesine sahip unsurlar olarak yiyecek, hizmet ve çevre ile ilişkili özelliklerin belirleyici olduğunu ortaya koymaktadır (Liu ve Jang, 2009). Literatürde yer alan konu ile ilgili birçok 
çalışma, adı geçen unsurların restoran deneyiminden memnuniyeti etkileyen unsurlar olarak önemi ortaya koymaktadır (Qu, 1997; Namkung ve Jang, 2007; Pettijohn vd., 1997; Ryu ve Jang, 2007).

Söz konusu üç temel unsur içerisinde yiyecekler, bir restoranın ana ürünü olması itibariyle ön plana çıkmaktadır. Literatürde yiyecekler başlığı altında, yemeğin lezzeti, yiyeceklerin sunumu, tazeliği, içeriği, doyuruculuğu, servis sıcaklığı ve menü çeşitliliğine ait özelliklerin öne çıktığı görülmektedir (Qu, 1997; MacLaurin ve MacLaurin, 2000; Soriano, 2002; Sulek ve Hensley, 2004; Namkung ve Jang, 2007; Kala, 2020; Liu vd., 2020). Hizmet unsurları, yiyecek ile ilgili faktörlerin ardından, müşteri memnuniyeti ve buna bağlı davranışsal niyetleri etkileyen en önemli unsurdur. Literatürde hizmet başlığı altında sıklıkla yer alan faktörler ise, güvenilir ve tutarlı hizmet, güler yüzlü ve nazik personel, personelin mesleki bilgisi, personelin temizliği ve hijyeni, servis hızı, personelin menü bilgisi ve personelin özel isteklere karşı yaklaşımı olarak sıralanabilir (Stevens vd.,1995; Qu, 1997; Pettijohn, vd. 1997; Parasuraman vd., 2002; Yuksel ve Yuksel, 2003; Andaleeb ve Conway, 2006; Ladhari vd., 2008; Tran, 2020). Çevre veya ilgili literatürde sıklıkla ele alındığı haliyle atmosfer ise, bilinçli olarak planlandığında tüketicilerin satın alma ihtimalini artıran bir unsur olarak (Kotler, 1973), restoranlarda müzik, 1sı, rahatlık gibi özellikleri içerir (Ryu ve Jang, 2007). Bu özellikleriyle çevre, tüketicilerin restoran ziyaretlerinden memnuniyetlerini etkileyen önemli unsurlardan bir diğeri olarak ortaya çıkmaktadır (Taylor ve DiPietro, 2018; Çetinsöz, 2019).

İlgili çalışmalar söz konusu üç unsur dışında, restoran deneyiminden memnuniyeti ve davranısssal niyetleri etkileme kapasitesine sahip farklı belirleyiciler olduğunu ortaya koymaktadır. Fiyat uygunluğu, bu belirleyiciler arasında en çok değinilen faktör olarak ön plana çlkmaktadır (Bitner, 1990; 1992; Bei ve Chiao, 2001; Bolton vd., 2003; Xia vd., 2004; Andaleeb ve Conway, 2006; Koçoğlu ve Kalem, 2020). Bununla birlikte, ilgili çalışmalarda ele alınan unsurlar içerisinde, rezervasyon, park etme olanağı ve benzeri imkanlar da değerlendirilmiştir (Kivela vd., 1999; 2000). Yiyecek, hizmet ve atmosfer dışında kalan müşteri memnuniyeti unsurları literatür kapsamında sıklıkla "kolaylık" başlığı altında sınıflandırılmıştır (Kim vd., 2006; Kwun, 2011; Kim vd., 2014; Ing vd., 2019).

Restoranlarda müşteri memnuniyeti unsurları olarak, yiyecek, hizmet, atmosfer ve kolaylık başlıkları altında yer alan faktörler Tablo 1' de yer almaktadır. Tablo hazırlanırken literatürde yer alan konu ile ilgili toplam 85 çalışma incelenmiş ve söz konusu çalışmalarda yer alan ve restoran deneyiminden memnuniyeti etkileyen unsurlara ait özelliklerden en sık yer verilenler derlenmiş ve bu doğrultuda sıralanmıştır. Bu çalışmalar içerisinde, söz konusu özellikleri, literatürden benzer şekilde derleyen çeşitli çalışmalara da rastlanmıştır (Ramanathan vd., 2016; Özdemir, 2019; Albayrak, 2014).

Tablo 1'de da anlaşılacağı haliyle, İlgili literatürde restoran deneyiminden memnuniyeti etkileyen unsurların ele alınma sıklığı incelendiğinde, bu unsurlar içerisinde sırasıyla yiyecek ile ilgili unsurlar, hizmet ile ilgili unsurlar, atmosfer ile ilgili unsurlar ve kolaylık ile ilgili unsurların ön plana çıktığı görülmektedir. Söz konusu unsurların altında yer alan çeşitli faktörler de bu sıklı̆̆a uygun olarak sıralanmış ve çalışmanın yöntem kısmında oluşturulan model için referans teşkil etmesi sağlanmıştır. 
Tablo 1. Restoran Deneyiminden Müşteri Memnuniyeti Unsurları

\begin{tabular}{|c|c|}
\hline \multirow[t]{8}{*}{ Yiyecek } & Yemeğin lezzeti \\
\hline & Yiyeceklerin sunumu \\
\hline & Yiyeceklerin tazeliği \\
\hline & Yiyeceklerin içeriği \\
\hline & Yiyeceklerin doyuruculuğu (Porsiyon miktarı) \\
\hline & Uygun yiyecek sıcaklığı \\
\hline & Menünün çeşitliliği \\
\hline & Diğer özellikler (Örn. Anlaşılır menü, güncel öğeleri içeren menü) \\
\hline \multirow[t]{8}{*}{ Hizmet } & Güvenilir ve tutarlı hizmet \\
\hline & Güler yüzlü ve nazik personel \\
\hline & Personelin mesleki bilgisi \\
\hline & Personelin temizliği ve hijyeni \\
\hline & Servis hızı \\
\hline & Personelin menü bilgisi \\
\hline & Personelin özel isteklere yaklaşımı \\
\hline & Diğer özellikler (Örn: personelin gıda alerjisi bilgisi, yabancı dil bilgisi) \\
\hline \multirow[t]{9}{*}{ Atmosfer } & İç dizayn ve dekor \\
\hline & Rahatlik \\
\hline & Yemek salonunun temizliği \\
\hline & Ortamin 1sisi \\
\hline & Müzik \\
\hline & Işıklandırma \\
\hline & Havalandırma \\
\hline & Manzara \\
\hline & Diğer özellikler (Örn: Restoranın dış görünüşü, mutfağın izlenebilirliği) \\
\hline \multirow[t]{8}{*}{ Kolaylık } & Menü fiyatlarının makul olması \\
\hline & Ulaşılabilirlik \\
\hline & Restoran bilinirliği \\
\hline & Fiyatların açık olarak belirtilmesi \\
\hline & İnternet ve telefon rezervasyon imkanı \\
\hline & Park yeri olanakları \\
\hline & Ödeme seçenekleri \\
\hline & Diğer özellikler (Örn: Bekleme salonu, çalışma saatleri) \\
\hline
\end{tabular}

Kaynak: İlgili literatürden yazar tarafından derlenmiştir.

\section{Gülez Yöntemi ve Kullanıldığı Alanlar}

Gülez (1990) tarafından bir orman içi alanın rekreasyon potansiyelinin değerlendirilmesi için kullanılan Gülez yöntemi, bir alanın rekreasyon potansiyelini belirlemede, peyzaj değeri, iklim değeri, ulaşılabilirlik, rekreatif kolaylık ve olumsuz etkenler olmak üzere 5 unsur altında toplanan ifadelerin puanlanmasıyla uygulanmaktadır. İfadelere verilen toplam puanlar en çok 100 olacağından, yöntemin uygulanmasıyla elde edilen toplam puan bir yerin orman içi rekreasyon potansiyelini yüzde olarak ifade etmektedir. Gülez yönteminin formulasyonu, Peyzaj değeri + İklim değeri + Ulaşılabilirlik + Rekreatif kolaylık + Olumsuz etkenler $=\%$ Rekreasyon potansiyeli şeklinde oluşturulmuştur. Modelde unsurların alabileceği en yüksek puanlar, her unsur için farklı ağırlıklarda olacak şekilde hesaplanmıştır. Tablo 2'de, Gülez yöntemi içerisinde yer alan unsurlara ait maksimum puanların dağılımı yer almaktadır. 
Türk Turizm Araştırmaları Dergisi, 5(1): 299-312.

Tablo 2. Gülez Yönteminde Yer Alan Unsurlara Ait Maksimum Puanların Dağılımı

\begin{tabular}{|c|c|c|}
\hline Sembol & Anlamı & Maksimum Puan \\
\hline $\mathrm{P}$ & Peyzaj değeri & 35 \\
\hline$\dot{\mathrm{I}}$ & İklim değeri & 25 \\
\hline $\mathrm{U}$ & Ulaşlabilirlik & 20 \\
\hline RK & Rekreatif kolaylık & 20 \\
\hline OSE & Olumsuz etkenler & -10 \\
\hline \%RP & Rekreasyon potansiyeli & 100 \\
\hline
\end{tabular}

Kaynak: Gülez (1990: 134).

Gülez yöntemi içerisinde yer alan unsurların alacağı toplam puanlar ise söz konusu unsurların içerisindeki faktörlerin aldığı puanların toplamıyla hesaplanır. Örneğin iklim değeri unsurunun ve iklim değeri altında yer alan faktörlerin alabileceği maksimum puanın hesaplanması formülü, Sıcaklık (10) + Yağış (8) + Güneşlenme (5) + Rüzgarlılık (2) = İklim değeri (25) şeklindedir.

İklim değeri unsurunun hesaplanması örneğinde yer alan faktörlerin puanlanabilmesi için modelde açıklamalar mevcuttur. Buna göre örneğin "rüzgarlılık" faktörünün puanlanması için yapılan açılama, yaz aylarında ortalama rüzgar hızının $1 \mathrm{~m} / \mathrm{sec}^{\prime} \mathrm{den}$ az (2 puan) veya 1-3 $\mathrm{m} / \mathrm{sec}$ (1 puan) olmasıyla ilişkilendirilmiştir.

Gülez yönteminde bir orman içi alanın rekreasyon potansiyelinin düzeyi, modelde yer alan referans değerler aracılığıyla belirlenir. Yöntem hem bir orman içi alanın mevcut durumdaki rekreasyon potansiyelini hem de planlanan düzenlemeleri dikkate alarak gelecekteki potansiyelini yansıtma kapasitesine sahiptir (Gülez, 1990). İlgili referasn değerler Tablo 3’de yer almaktadır.

Tablo 3. Orman İçi Rekreasyon Potansiyelinin Saptanması

\begin{tabular}{|c|c|c|}
\hline Orman içi rekreasyon potansiyeli & Çok düşük & \%30'dan düşük \\
\hline Orman içi rekreasyon potansiyeli & Düşük & $\% 30-\% 45$ \\
\hline Orman içi rekreasyon potansiyeli & Orta & $\% 46-\% 60$ \\
\hline Orman içi rekreasyon potansiyeli & Yüksek & $\% 61-\% 75$ \\
\hline Orman içi rekreasyon potansiyeli & Çok yüksek & \%75'den yüksek \\
\hline
\end{tabular}

Kaynak: Gülez, (1990: 139).

Gülez yöntemi birçok çalışma kapsamında, açı alanların rekreasyon potansiyelini değerlendiren benzer araştırmaların yöntemi olarak ele alınmıştır (Akten, 2003; Yılmaz vd., 2009; Korkut ve Şimşek, 2009; Surat, 2017; Özçalık ve Kumru, 2019). Bununla birlikte Gülez (1990), yöntemin yüzme, sportif balıkçllı, gezinti, tırmanıcılık gibi orman içi rekreasyon faaliyetlerine uyarlanabilir olduğunu ve bu alanlarda da kullanılması için geliştirilebileceğini belirtmiştir. Aynı zamanda yöntemin turizm alanında da özellikle resort otellerin rekreasyonel çekiciliğinin belirlenmesi için uygun bir yöntem olarak kullanılabileceği değerlendirilmiştir (Gürbüz, 2019).

Gülez yönteminin farklı alanlarda kullanımına yönelik önerilerin, yöntemde yer alan modelin çok yönlü olmasından dolayı geniş bir özellikler bütününün değerlendirilmesine imkan tanımasından, ayn zamanda da modelde yer alan puanların toplamının yüz puan olmasıyla, herhangi bir araştırmaya yönelik istatistiği direk olarak yüzde hesabıyla verme yeteneğinden kaynaklandığı ifade edilebilir. Yönteme ilişkin bu esneklik neticesinde, restoran deneyiminden memnuniyet unsurlarını içerecek şekilde yeniden düzenlenebileceği ve böylece de restoranları 
tüketiciyi memnun etme potansiyelini ortaya koyan somut neticelere ulaşma konusunda verimli alacağı düşünülmüştür.

\section{YÖNTEM}

Çalışma kapsamında ele alınan restoran deneyiminden memnuniyet unsurları ve bu unsurlar altında yer alan faktörler, Tablo 1 'de yer aldığı haliyle, literatürde konu ile ilgili çalışmalar kapsamında en sık ele alınan faktörler başta olmak üzere sıralanmıştır. Kavramsal çerçeve içerisinde detaylı olarak tanımlanan Gülez'in (1990) çalışmasında orman içi rekreasyon potansiyelini belirlemek üzere geliştirilen yöntem baz alınarak, restoran deneyiminden memnuniyet unsurları ve bu unsurlar altında yer alan faktörlere ilişkin maksimum puanlar tanımlanmıştır. Söz konusu faktörler ve bu faktörlere ait puanlamalar, Gülez yönteminden uyarlanan modele yerleştirilmiştir.

\section{BULGULAR}

Restoranların tüketicileri memnun etme düzeyini ölçmek üzere hazırlanan modelde yer aldığ haliyle "sunulan yiyeceğin değeri" unsuru otuz beş, "sunulan hizmetin değeri" unsuru yirmi beş, "atmosfer" unsuru yirmi, "kolaylık" unsuru ise yirmi maksimum puanla puanlandırılmıştır. Böylece literatürde restoran deneyiminden memnuniyeti birincil düzeyde etkilediği belirtilen unsurlar olarak yiyecekler ve hizmet ve bu unsurlar içerisinde yer alan faktörler modelde $\% 60$ ile temsil edilmektedir. Modelin $\% 40$ '1 ise atmosfer ve kolaylık unsurlarının etkisine dayanır. Bununla birlikte Gülez yöntemini oluşturan kavramsal modelde yer alan "olumsuz etkenler" ile ilişkilendirilebilecek faktörler de bu aşamada modele dahil edilmiştir. Restoran deneyiminden memnuniyeti değerlendirmek için kullanılan faktörlerin hâlihazırda, olumlu veya olumsuz değerlendirmeye göre puanlanması beklendiğinden, bu faktörlere olumsuz etkenler içerisinde yer verilmemiştir. Böylece olumsuz etkenler içerisinde, daha önceki faktörler içerisinde yer verilmeyen ancak literatürde yer alan ve olumsuzluk belirten, kalabalık, gürültü, kötü koku gibi etkenler yer almıştır. Olumsuz etkenler model kullanılarak elde edilecek toplam puana eksi on puanlık bir etki edebilir. Ayrıca modelde belirtilen faktörler arasında yer almayan ancak tüketici deneyimine etkisi değerlendirilebilecek diğer faktörlerin puanlanabilmesi için her başlık altında "diğer" ifadesi de yer almaktadır. Tablo 4, Gülez yöntemi baz alınarak restoran deneyiminden memnuniyet unsurlarının değerlendirilmesi doğrultusunda hazırlanan modeli içermektedir.

Tablo 4. Restoran Deneyiminden Memnuniyet Potansiyeli Değerlendirme Modeli

\begin{tabular}{|c|c|c|c|c|c|}
\hline $\begin{array}{l}\text { Formüldeki } \\
\text { öğeler }\end{array}$ & $\begin{array}{l}\text { Değerlendirme } \\
\text { puanı }\end{array}$ & Öğenin özellikleri & $\begin{array}{l}\text { Maksimum } \\
\text { puan }\end{array}$ & Açıklama & \\
\hline \multirow{8}{*}{$\begin{array}{l}\text { Sunulan } \\
\text { Yiyeceğin } \\
\text { Değeri }\end{array}$} & & Yemeğin lezzeti & 6 & \multirow{8}{*}{$\begin{array}{l}\text { Çok lezzetli } \\
\text { Orta derecede lezzetli } \\
\text { Düşük lezzetli } \\
\text { Çok çekici } \\
\text { Orta derecede çekici } \\
\text { Çekici değil } \\
\text { Çok taze } \\
\text { Orta derecede taze } \\
\text { Taze değil }\end{array}$} & $5-6$ puan \\
\hline & & & & & 3-4 puan \\
\hline & & & & & 1-2 puan \\
\hline & & Yiyeceklerin & 5 & & 4-5 puan \\
\hline & & sunumu & & & 2-3 puan \\
\hline & & Yiyeceklerin & 5 & & 4-5 puan \\
\hline & & tazeliği & & & 2-3 puan \\
\hline & & & & & 1 puan \\
\hline
\end{tabular}




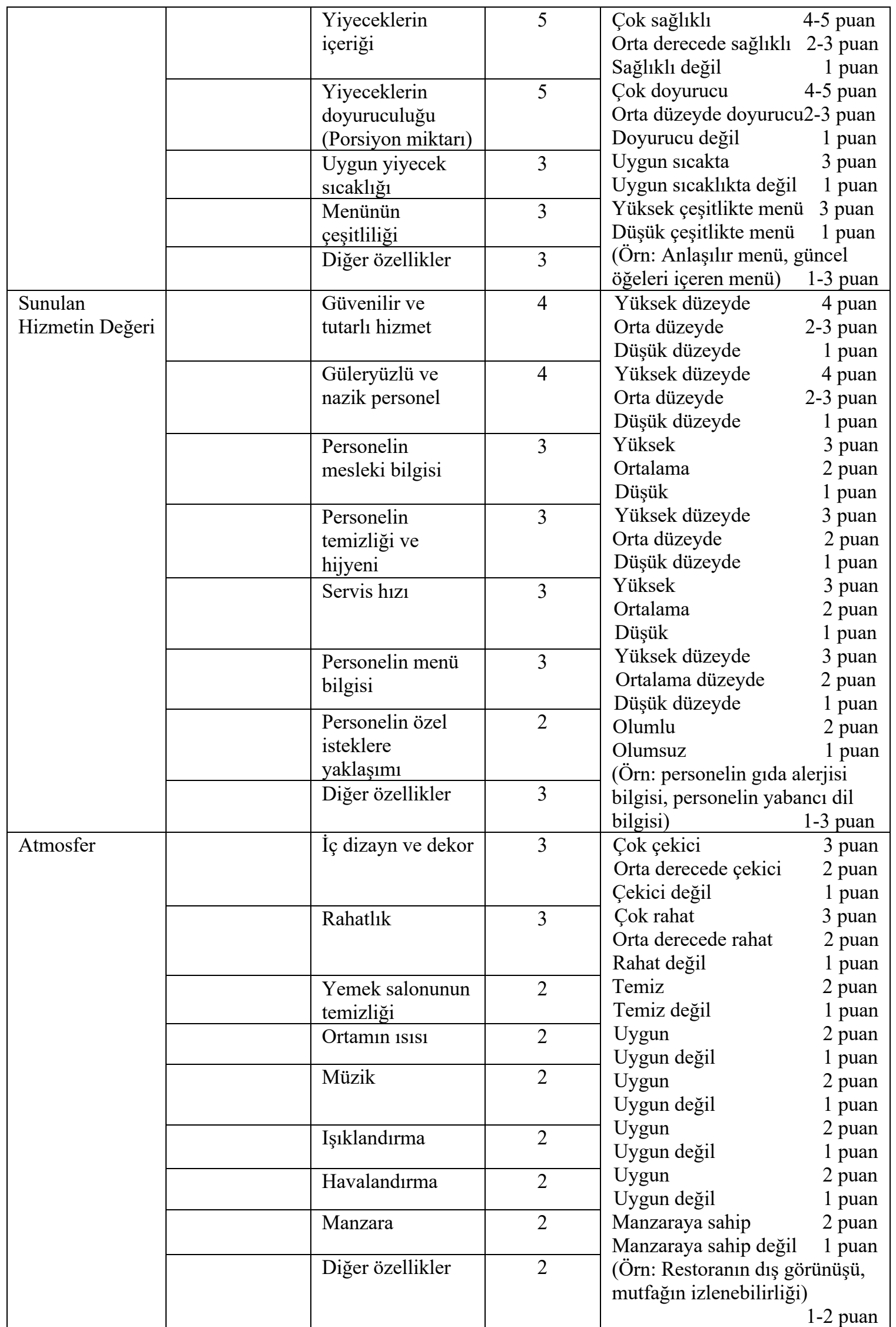




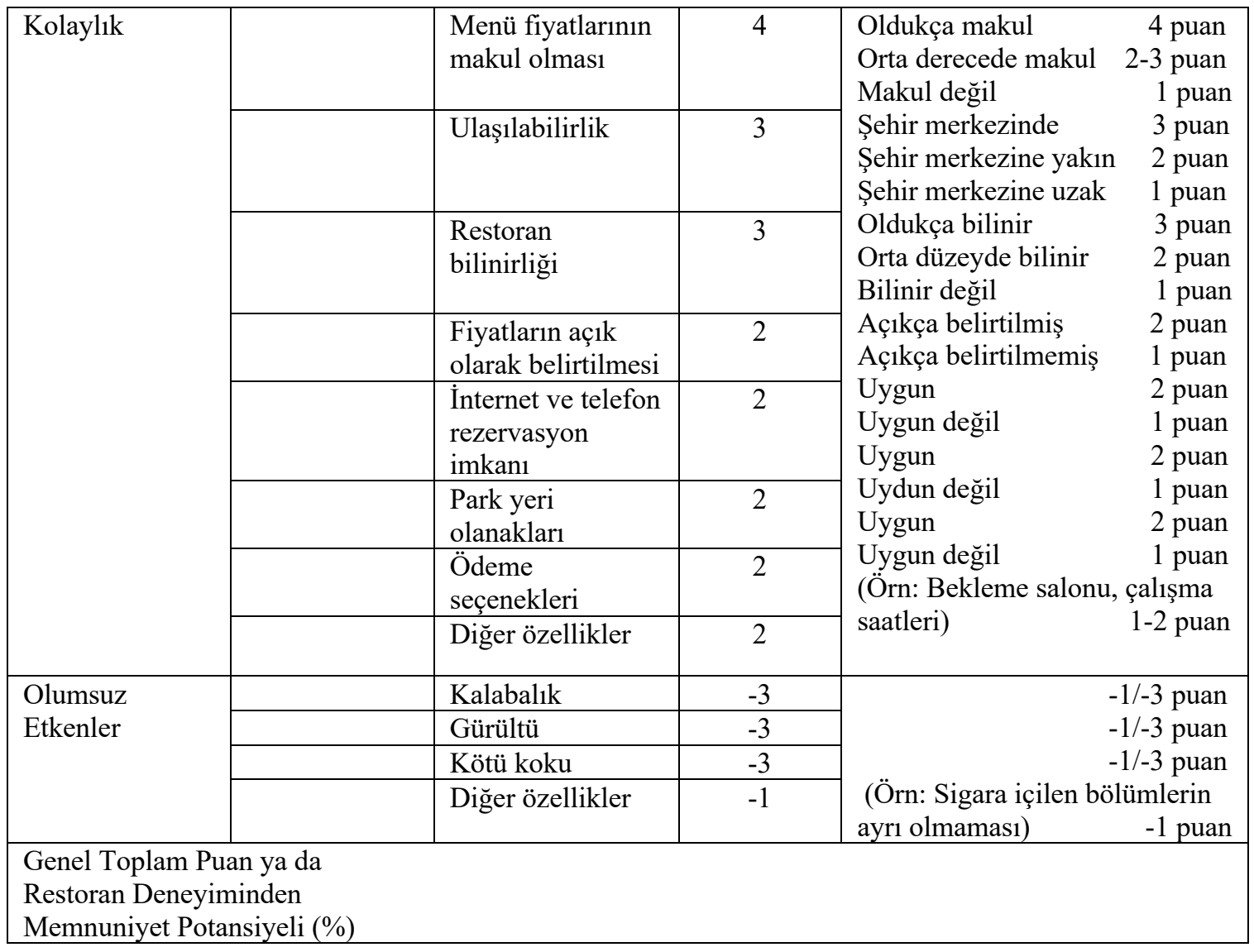

Kaynak: Yazar tarafından oluşturulmuştur.

Modelde toplam puan veya yüzde değeri, unsurlara ait tüm ifadelere verilen puanların toplanmasıyla elde edilir. Modelden elde edilen toplam puanlar neticesinde, restoran deneyiminden memnuniyet potansiyeli, referans değerler aracılığıyla belirlenir. Buna göre bir restoranın -tüketicilere yaşattığı deneyimin memnuniyet yaratmasına yönelik- potansiyeli çok düşük (\%30 ve altı), düşük (\%30 ve $\% 45$ arası), orta seviyede (\%46 ve $\% 60$ arası), yüksek (\%61 ve \%75 aras1) veya çok yüksek (\%75 ve üzeri) olabilmektedir. İlgili referans değerler Tablo 5 'de yer almaktadir.

Tablo 5. Restoran Deneyiminden Memnuniyet Potansiyeli

\begin{tabular}{|l|c|c|}
\hline $\begin{array}{l}\text { Restoran Deneyiminden } \\
\text { Memnuniyet Potansiyeli }\end{array}$ & Çok düşük & \%30'dan düşük \\
\hline $\begin{array}{l}\text { Restoran Deneyiminden } \\
\text { Memnuniyet Potansiyeli }\end{array}$ & Düşük & $\% 30-\% 45$ \\
\hline $\begin{array}{l}\text { Restoran Deneyiminden } \\
\text { Memnuniyet Potansiyeli }\end{array}$ & Orta & $\% 46-\% 60$ \\
\hline $\begin{array}{l}\text { Restoran Deneyiminden } \\
\text { Memnuniyet Potansiyeli }\end{array}$ & Yüksek & $\% 61-\% 75$ \\
\hline $\begin{array}{l}\text { Restoran Deneyiminden } \\
\text { Memnuniyet Potansiyeli }\end{array}$ & Çok yüksek & $\% 75^{\prime}$ den yüksek \\
\hline
\end{tabular}

Kaynak: Yazar tarafından oluşturulmuştur. 


\section{TARTIŞMA, SONUÇ ve ÖNERİLER}

Restoranların sundukları deneyim neticesinde tüketici memnuniyeti sağlama potansiyelini değerlendirmek ve söz konusu değerlendirme aracılığıyla somut bir değer ortaya koymak üzere hazırlanan model, restoran deneyiminden memnuniyet unsurları ve bu unsurların altında yer alan faktörleri yansıtma kapasitesi itibariyle, literatürü temsil etme yeterliliğine sahiptir. Bu durum, modelin literatürde restoran deneyiminden memnuniyetle ilişkili faktörleri geniş bir çerçeveden ele alması ile açıklanabilir.

Bununla birlikte çalışma kapsamında restoranların tüketiciyi memnun etme potansiyelini somut olarak yansıtması beklenen bu modelin, uyarlandığı model (Gülez, 1990) itibariyle bazı yapısal özelliklere sahip olduğunu belirtmek gerekmektedir. Söz konusu özellikler, öncelikle Gülez (1990)'in çalışmasında da ortaya koyulduğu haliyle, modelin sağladığı birtakım avantaj ve dezavantajlara vurgu yapmaktadır.

Gülez (1990)'in modele ilişkin olarak öngördügü avantajlardan, pratik ve kolay uygulanabilir olma durumunun, restoranların tüketici memnuniyeti sağlama potansiyelinin belirlenmesi aşamasında bir avantaj olarak değerlendirilmesi mümkündür. Modelin yapısından kaynaklı bir diğer avantaj da söz konusu potansiyeli ortaya koyacak birçok farklı unsurla temsil edilmesi, ortaya çıkabilecek olumsuzlukların hangi unsurlardan kaynaklandığının net olarak tespit edilebilmesi ve bu olumsuzlukların ortadan kaldırılabilmesinde kolay müdahale imkanı sağlaması olarak ifade edilebilir. Ayrıca model bu özelliği ile, yalnızca restoranın tüketiciyi menün etme potansiyelini ortaya koymakla kalmamakta, ilgili unsurlar bağlamında yapılacak değişikliklerin, memnuniyet potansiyelini ne düzeyde değiştireceğine yönelik gelecek projeksiyonu yapmaya da olanak tanımaktadır.

Diğer yandan, ilgili modelin (Gülez, 1990) yapısından kaynaklı birtakım dezavantajlar da bulunmaktadır. Söz konusu dezavantajlardan ilki modelin sübjektif bir eğilim göstermesidir (Gülez, 1990). Ayrıca, bu çalışma kapsamında geliştirilen modelin ortaya koyacağı sonuçların, uyarlandığ1 modele göre daha yüksek bir sübjektiflik ihtimalini beraberinde getirdiği söylenebilir. Bu durumun, özellikle yiyecek değeri ile ilişkilendirilen birtakım faktörlere yönelik puanlamaların gerçekleştirilmesinde duyusal değerlendirmelere ihtiyaç duyulmasının gerekliliği neticesinde ortaya çıkabilecek bir sonuç olduğundan bahsetmek mümkündür. Gülez (1990)'in çalışmasında yer alan modeldeki faktörlere ait açıklamaların ise, çoğunlukla fiziksel ve meteorolojik değerlendirmeler ile olanakları kapsaması itibariye, büyük ölçüde gözlem yoluyla toplanabilecek verilere ihtiyaç duyduğu ve yöntemin sübjektif yapısının yarattığı dezavantajın ele alınan alanlara ilişkin uzman değerlendirmeleriyle bertaraf edilebilmesinin kısmen mümkün olduğu söylenebilir.

Modele ilişkin olarak bahsi geçen bu dezavantajın ortadan kaldırılmasında, model kapsamında yer alan faktörleri içeren formun, restoran deneyiminden memnuniyeti ölçmek için hâlihazırda kullanılan ve restoranı ziyaret eden tüketicilere uygulanan veri toplama yöntemlerine benzer şekilde doğrudan bir veri toplama aracı olarak kullanılması önerilebilir. Form kullanılarak toplanacak verilerin büyüklüğünün, evreni temsil etme kabiliyetine sahip olmasının sağlanması böylece, bahsi geçen sübjektiflik dezavantajını ortadan kaldırabilecektir. Modelin, restoranların tüketiciyi memnun etme potansiyelini belirlemek için tadım uzmanları başta olmak üzere alanında uzman kişilerce kullanılması da ayrıca modelin verimliliğini test etmek için bir yöntem olarak değerlendirilebilir.

Modele ilişkin bir diğer dezavantaj ise, modelde yer alan faktörlerin bazı restoranların değerlendirilmesinde yetersiz kalabileceği öngörüsüdür. Bu durum özellikle etnik restoranlar gibi otantiklik açısından benzersiz ve tüketicilerce talep edilen özelliklere sahip olması beklenen restoranlar için geçerli olmakla birlikte, bazı konsept restoranlar için de önemli olabilecektir. Bu 
durumda, bahsi geçen restoranların tüketicileri memnun etme potansiyellerini belirlemek amacıyla kullanımı için modele, ilgili literatür taraması aracılığıyla belirlenecek yeni faktörlerin eklenmesi gerekebilecek ve modelin böylece farklı özelliklere sahip restoranlar kapsamında kullanımı da mümkün olabilecektir.

$\mathrm{Bu}$ çalışma kapsamında oluşturulan model, bir restoranın tüketici memnuniyeti yaratma potansiyelini somut bir yüzde değeri olarak ortaya çıarıyor oluşu neticesinde, restoran deneyiminden müşteri memnuniyetini ele alan ilgili literatüre katkısı itibariyle önemlidir. Bu hususta modelin bahsedilen avantajları kullanabilme ve dezavantajları bertaraf edebilme yeteneği yönelik öngörüleri doğrulamak, ancak gelecek çalışmalarda restoranlardan elde edilecek verilerin model kapsaminda belirlenen puanlamalar doğrultusunda değerlendirilebilirliği ve restoran deneyiminden memnuniyet potansiyeli yüzdesine ulaşılabilirlik yoluyla test edilebilecektir.

\section{KAYNAKÇA}

Akten, M. (2003). Isparta ilindeki bazı rekreasyon alanlarının mevcut potansiyellerinin belirlenmesi. Türkiye Ormancilik Dergisi, 4(2), 115-132.

Albayrak, A. (2014). Müşterilerin restoran seçimlerini etkileyen faktörler: İstanbul örneği. Anatolia: Turizm Araştırmaları Dergisi, 25(2), 190-201.

Almanza, B. A., Jaffe, W. and Lin, L. (1994). Use of the service attribute matrix to measure consumer satisfaction. Hospitality Research Journal, 17(2), 63-75.

Andaleeb, S. S., and Conway, C. (2006). Customer satisfaction in the restaurant industry: an examination of the transaction-specific model. Journal of Services Marketing, 20(1), 3-11.

Bei, L. T., and Chiao, Y. C. (2001). An integrated model for the effects of perceived product, perceived service quality, and perceived price fairness on consumer satisfaction and loyalty. Journal of Consumer satisfaction, Dissatisfaction and Complaining Behavior, 14, 125-140.

Berry, J. W., Berry, J. W., Poortinga, Y. H., Segall, M. H. and Dasen, P. R. (2002). Cross-cultural psychology: Research and applications. Cambridge University Press.

Bilgin, Y. (2017). Restoran işletmelerinde hizmet kalitesi, müşteri memnuniyeti ve müşteri sadakatinin ağızdan ağıza pazarlamaya etkisi, İşletme Araştırmaları Dergisi, 9(4), 33-62.

Bitner, M. J. (1990). Evaluating service encounters: the effects of physical surroundings and employee responses. Journal of Marketing, 54(2), 69-82.

Bolton, L. E., Warlop, L. and Alba, J. W. (2003). Consumer perceptions of price (un) fairness. Journal of Consumer Research, 29(4), 474-491.

Çetinsöz, B. C. (2019). Influence of physical environment on customer satisfaction and loyalty in upscale restaurants, Journal of Tourism and Gastronomy Studies, 7(2), 700-716.

Gülez, S. (1990). Orman içi rekreasyon potansiyelinin saptanması için geliştirilen bir değerlendirme yöntemi, İstanbul Üniversitesi Orman fakültesi Dergisi, 40(2). 132-147.

Gürbüz, A. K., (2019). Rekreasyon ve Mekân, http://alikemalgurbuz.com/rekreasyon-ve-mekan/, E.T. 29.09.2020.

Ing, P. G., Lin, N. Z., Xu, M. and Thurasamy, R. (2019). Customer loyalty in Sabah full-service restaurant. Asia Pacific Journal of Marketing and Logistics, 32(7), 1407-1429. 
Kala, D. (2020). Examining the impact of food attributes and restaurant services on tourist satisfaction: evidence from mountainous state of India, Journal of Quality Assurance in Hospitality $\mathcal{E}$ Tourism, 21(4), 430-453.

Kim, B. M., Kim, H. M., Kim, Y. H. and Yoon, J. Y. (2014). The affects of convenience and atmosphere attributes on new seniors' restaurant selection. Journal of the East Asian Society of Dietary Life, 24(1), 12-19.

Kivela, J., Inbakaran, R. and Reece, J. (1999). Consumer research in the restaurant environment, Part 1: A conceptual model of dining satisfaction and return patronage. International Journal of Contemporary Hospitality Management, 11(5), 205-222.

Kivela, J., Inbakaran, R. and Reece, J. (2000). Consumer research in the restaurant environment. Part 3: analysis, findings and conclusions. International Journal of Contemporary Hospitality Management, 12(1), 13-30.

Koçoğlu, C.M. and Kalem, M.Y. (2020). Research on the impact of perceived service fairness and price fairness on the complaining behaviour of restaurant customers. Journal of Business, Economics and Finance (JBEF), 9(1), 1-11.

Korkut, D. S. A. ve Şimşek, D. (2009). Kıyı şeridi rekreasyon potansiyelinin belirlenmesinde bir yöntem uygulaması: Tekirdağ merkez ilçe örneği. Tekirdă̆ Ziraat Fakültesi Dergisi, 6(3), 315-327.

Kotler, P. (1973). Atmospherics as a marketing tool. Journal of Retailing, 49(4), 48-64.

Kwun, D. J. W. (2011). Effects of campus foodservice attributes on perceived value, satisfaction, and consumer attitude: A gender-difference approach. International Journal of Hospitality Management, 30(2), 252-261.

Ladhari, R., Brun, I. and Morales, M. (2008). Determinants of dining satisfaction and post-dining behavioral intentions. International Journal of Hospitality Management, 27(4), 563-573.

Lee, Y. L. and Hing, N. (1995). Measuring quality in restaurant operations: an application of the SERVQUAL instrument. International Journal of Hospitality Management, 14(3-4), 293-310.

Liu, Y. and Jang, S. S. (2009). Perceptions of Chinese restaurants in the US: what affects customer satisfaction and behavioral intentions?. International Journal of Hospitality Management, 28(3), 338348.

Liu, Y., Song, Y., Sun, J., Sun, C., Liu, C. and Chen, X. (2020). Understanding the relationship between food experiential quality and customer dining satisfaction: A perspective on negative bias. International Journal of Hospitality Management, 87, 1-12.

MacLaurin, D. J. and MacLaurin, T. L. (2000). Customer perceptions of Singapore's theme restaurants. Cornell Hotel and Restaurant Administration Quarterly, 41(3), 75-85.

Namkung, Y. and Jang, S. (2007). Does food quality really matter in restaurants? Its impact on customer satisfaction and behavioral intentions. Journal of Hospitality $\mathcal{E}$ Tourism Research, 31(3), 387-409.

Oh, H. and Jeong, M. (1996). Improving marketers' predictive power of customer satisfaction on expectation-based target market levels. Hospitality Research Journal, 19(4), 65-85.

Özçalık, M. ve Kumru, S. N. (2019). Kapıçam tabiat parkı'nın Gülez yöntemine göre rekreasyon potansiyelinin belirlenmesi. Turkish Journal of Forest Science, 3(2), 129-141. 
Parasuraman, A. and Zinkhan, G. M. (2002). Marketing to and serving customers through the Internet: An overview and research agenda. Journal of The Academy of Marketing Science, 30(4), 286295.

Pettijohn, L. S., Pettijohn, C. E. and Luke, R. H. (1997). An evaluation of fast-food restaurant satisfaction: determinants, competitive comparisons and impact on future patronage. Journal of Restaurant \& Foodservice Marketing, 2(3), 3-20.

Qu, H. (1997). Determinant factors and choice intention for Chinese restaurant dining: a multivariate approach. Journal of Restaurant \& Foodservice Marketing, 2(2), 35-49.

Ramanathan, R., Di, Y. and Ramanathan, U. (2016). Moderating roles of customer characteristics on the link between service factors and satisfaction in a buffet restaurant. Benchmarking: An International Journal, 23(2), 469-486.

Reuland, R., Choudry, J. and Fagel, A. (1985). Research in the field of hospitality. International Journal of Hospitality Management, 4(4), 141-146.

Ryu, K. and Jang, S. S. (2007). The effect of environmental perceptions on behavioral intentions through emotions: The case of upscale restaurants. Journal of Hospitality $\mathcal{E}$ Tourism Research, 31(1), 56-72.

Soriano, D. R. (2002). Customers' expectations factors in restaurants: The situation in Spain, International Journal of Quality \& Reliability Management, 19(8-9),1055-1067.

Stevens, P., Knutson, B. and Patton, M. (1995). DINESERV: A tool for measuring service quality in restaurants. The Cornell Hotel and Restaurant Administration Quarterly, 36(2), 5-60.

Sulek, J. M. and Hensley, R. L. (2004). The relative importance of food, atmosphere, and fairness of wait: The case of a full-service restaurant. Cornell Hotel and Restaurant Administration Quarterly, 45(3), 235-247.

Surat, H. (2017). Evaluation of the recreational potential of Deriner Dam Reservoir and according to Gulez method and development of land use proposals. Kahramanmaraș Sütçü İmam Üniversitesi Doğa Bilimleri Dergisi, 20(3), 247-257.

Taylor Jr, S. and DiPietro, R. B. (2018). Generational perception and satisfaction differences related to restaurant service environment. International Journal of Hospitality \& Tourism Administration, 19(4), 374-396.

Tran, V. D. (2020). Assessing the effects of service quality, experience value, relationship quality on behavioral intentions. The Journal of Asian Finance, Economics, and Business, 7(3), 167-175.

Uslu, A. (2020). The relationship of service quality dimensions of restaurant enterprises with satisfaction, behavioral intention, eWOM and the moderator effect of atmosphere, Tourism $\mathcal{E}$ Management Studies, 16(3), 23-35.

Xia, L., Monroe, K. B. and Cox, J. L. (2004). The price is unfair! A conceptual framework of price fairness perceptions. Journal of Marketing, 68(4), 1-15.

Yen-Soon Kim, Patrick J. Moreo and Ronnie J. M. Yeh (2006) Customers' Satisfaction Factors Regarding University Food Court Service, Journal of Foodservice Business Research, 7(4), 97-110.

Yılmaz, H., Karaşah, B. ve Yüksel, E. E. (2009). Gülez yöntemine göre Kafkasör kent ormanının rekreasyonel potansiyelinin değerlendirilmesi. Artvin Çoruh Üniversitesi Orman Fakültesi Dergisi, 10(1), 53-61. 
Yüksel, A. and Yüksel, F. (2003). Measurement of tourist satisfaction with restaurant services: A segment-based approach. Journal of Vacation Marketing, 9(1), 52-68. 